\title{
Research on the Influence of Media Violence on Youth
}

\author{
Xufang Guo \\ ${ }^{1}$ University of Wisconsin Stevens Point, Stevens Point, Wisconsin, the United States, 54481 \\ *Corresponding author. Email: Xguo608@gmail.com
}

\begin{abstract}
Media use by children and teenagers has increased substantially in these years, in part because of the recent increase in mobile phone use by children and teenagers. About three-quarters of teenagers now own smartphones, and more than half say they are online "often" and "addicted" to their phones. The impact of the media on society and individuals with violent themes and descriptions is increasingly being noticed. A larger amount of research evidence shows that those violence scene in media such as television, films, music, and video games poses a serious threat to the mental health of youth. This article will be addressed on effects of violent videos on young people, namely, inducing aggressive behavior, reducing prosocial behavior and inducing violent desensitization. The findings suggest that experts have reached a consensus on the reality of the impact of violent media on children. Experimental studies have conclusively shown that in the short term, exposure of children and adults to media violence will immediately increases the possibility of having aggressive behavior, decreases prosocial behavior and triggers violent desensitization. Longitudinal experimental studies also shows convincingly evidence and the result shows that children's exposure to electronic media violence will lead to a long-term increase in their risk of exhibiting aggressive and violent behavior.
\end{abstract}

Keywords: media violence, media influence, prosocial behavior, desensitization

\section{INTRODUCTION}

In the 21 st century, mass media has occupied most of our daily lives. In such a new environment, television, radio, movies, video games, computers and mobile phones play a central role in children's daily life. However, violence in electronic media is as common as it is. Due to the widespread of social media, more and more children and teenagers are exposed to violent media. According to a US poll, children aged 8 to 12 are exposed to entertainment media for an average of nearly six hours a day, with more than 4.5 hours of screen time. 13- to 18-year-olds have far more exposure: nearly nine hours of entertainment media and more than six and a half hours of screen time [1]. Violent media accounts for a large proportion of these mass media contacts. It has a negative effect on children and adolescents. The National Television Violence report shows that $61 \%$ of $\mathrm{TV}$ shows contain some violence. Only $4 \%$ of violent TV shows are antiviolence themed, or in other words, $96 \%$ of all violent TV shows to simply entertain viewers by using violence as a narrative, and the film's method [2]. There is also a growing body of research on the effects of violent media on children and adolescents. Although there has been a lot of research on the effects of violent media on young people over the past few decades, some people still fail to understand the negative effects of violent media on young people. This paper will focus on three negative effects of violent media.

\section{INFLUENCE OF MEDIA VIOLENCE}

\subsection{Definition of Violence and a Tendency to be Attracted to Violent Media}

Before discussing the impact of violent media on young people, it is important to define violence. Violence in screen entertainment media, people are easily to be exposed to video games, television, movies, and the Internet, is ubiquitous. It is defined as a description of characters or players trying to harm other characters or players [3]. Violence is also depicted in the popular media and often involves action scenes that increase physiological arousal, such as heart rate and blood pressure [4].

Although most teenagers have access to the media, not everyone is attracted to violent media and has bad 
effects. Studies have shown a link between exposure to violent video games and malicious personality tendencies. For instance, sadists may be predisposed to violent video games in the first place, and repeated exposure to violent video games can further increase their sadistic tendencies [5]. Men is more likely to play violent video games compare to women, which means man are more likely to be attracted to these games. This is partly because men are less empathetic than women, more likely to justify physical violence on moral grounds, and have a greater need for feeling and aggression in games [6]. Previous studies have shown that psychoticism and aggressive personality traits may mitigate the negative effects of violent video games (VVGs). The five-factor model of personality (FFM) was then used to classify, integrate these findings, and examine why these traits are important regulatory variables. Analysis suggests that these traits may moderate the impact of VVGs because they contain FFM traits: neuroticism (+), agreeableness (-), and conscientiousness (-). Research has shown that personality regulates an individual's tendency to react negatively to VVGs. VVGs only seem to adversely affect certain people, and those affected have preexisting personalities, such as high neuroticism, low likeability and low conscientiousness, that make them susceptible to this violent media [7].

\subsection{Trigger Aggressive Behavior}

Aggression is an act that intends to harm others whose motivation is to avoid such harm. It is not an emotion, a radical idea, plan or desire. This definition does not include accidental actions that cause injury, such as an out-of-control car accidentally hitting a pedestrian, but includes actions that are intended to cause injury even when an attempt fails, such as intentional killing but not hitting the target [8]. Since Albert Bandura's classic bobo doll study showed that children mimic physical attacks on inanimate objects they see on television, social learning theory has provided a convincing theoretical framework for understanding the effects of violent media. Experimental studies have shown that players act more aggressively right after playing violent games. These experimental studies usually involve participants to watch violent $\mathrm{TV}$ shows, movies or video games in a relatively short period before measuring aggression. In one study, one hundred and one students, which include 64 men and 37 women, were assigned to one of four experimental conditions randomly: the participants in a neutral offline or online video game is both 26 , the participants in a violent offline video game is 23 , and the participants in a violent online video game is 26 . After that, they completed questionnaires to assess their attitudes to the game and used the chili sauce paradigm, which is the participant prepared an amount of chili sauce for a taste tester whom they know couldn't stand hot chili sauce, to measure aggression. The results showed that participants who played violent video games showed more aggression than those who played the neutral video games [9]. Aggression is divided into physical aggression, relational aggression, indirect aggression, and social aggression. In the past, researchers have mostly focused on physical aggression, but in recent years, research has shifted to non-physical, covert forms of aggression. Indirect, social or relational aggression directed at social circumstances, status or relationships between people. In a longitudinal study that focused on relational aggression, the 467 participants listed their three favorite shows and rated viewing reviews for each show. Then, they completed a series of questionnaires about media and aggression at three different time points. The results showed that there was a longitudinal correlation between relationship aggression behavior watched on TV and future relationship aggression behavior [10]. Violent media triggering violent behavior has also been demonstrated through cognitive and neurophysiological aspects. In one study, 13 participants were recruited to take an MRI test based on questionnaire measurements. All participants played video games regularly, but most of the participants played violent games, while the rest played non-violent games. Participants underwent MRI scans while playing the game in both violent and nonviolent modes. The results showed that non-violent players increased emotional response areas while playing violent games, while violent players actively suppressed the same areas. In addition, non-violent players showed increased areas of attention and cognitive control, while violent players showed no change [11].

\subsection{Decreased Prosocial Behavior}

Prosocial behavior represents a broad category of behavior, which is defined by certain important parts of society and/or a person's social group as behavior that is generally beneficial to others. Prosocial behavior is defined as any voluntary behavior, such as sharing, praising, and helping, with the purpose of helping or benefiting others or groups. Prosocial behavior is related to several positive outcomes, including life satisfaction, self-perception, personal growth, autonomy, positive relationships with others, social consistency, and psychological functioning [12]. In a study on the relationship between media violence and prosocial behavior, participants listed their three favorite video games and scored how often they played each video game on a scale of 1(infrequent) to 5(very frequent). All the games identified by the participants were assigned to 320 independent raters, who were asked to rate the level of physical aggression in each game they were familiar with, which means they viewed regularly. Raters were provided with definitions and examples of physical aggression. The ratings were 
based on a Likert scale of 1(no physical aggression) to 5(very physical aggression). Children's prosocial behavior was measured using a nine-item dominance scale. Participants were asked on a 5-likert-style scale, from 1(not at all like me) to 5(very much like me), how much they disagreed with or agreed with statements about themselves. Sample statements included "I help people I don't know, even if it's not easy for me" and "I try to cheer up people who look sad, even if I don't know them." A higher score indicates a higher level of prosocial behavior. The results showed that violent videos were negatively correlated with prosocial behavior [13]. Prosocial behavior and aggressive behavior often appear simultaneously in violent media influences. A cross-sectional study examined seventh and eighth grade students at a school in Germany. The study looked at the relationship between these students' heavy use of violent media and their aggressive and prosocial behavior at school. The researchers divided media exposure into three genres, television, film and video games, and asked the students how often they watched those genres. Each genre of content in each genre was rated for violence and the average violence score was calculated. For participants, teachers rated aggressive and prosocial behavior by how often students helped others and how often students displayed aggressive behavior. The results showed that exposure to media violence was negatively correlated with prosocial behavior and positively correlated with aggressive behavior [14].

\subsection{Trigger Desensitization Phenomenon}

"Desensitization, the reduction of cognitive, emotional, and/or behavioral responses to a stimulus, is an automatic and unconscious phenomenon often experienced in typical, everyday life experiences" [15]. A study examining the association between violent media exposure, sympathetic skin conductance response (SCR) response, and changes in the left lateral orbitofrontal cortex (IOFC) activation in typically developing male adolescents aged 14-17 years. The study's SCR data analysis revealed adaptability over time, showing a linear decline in SCR as aggression increased in the video. For mild and moderately aggressive videos in the study, the study found SCR desensitization, suggesting that autonomic neural responses diminished over time when teens were exposed to more aggressive videos [16]. In another short-term violent desensitization to media study, participants were asked to watch different clips of violence and comedy, complete questionnaires before starting and at the end of each clip. Questionnaires included whether they liked movie clips and whether they felt sympathy for victims of violence. The study showed that subjects in terms of initial enjoyment levels of movie violence has a huge different from each other, but all participants followed the same pattern over time, which suggests that desensitization to media violence may occur after sustained exposure to media violence for a short period [17]. In an fMRI study, participants repeatedly watched videos showing varying levels of aggressive behavior. The results showed that aggressive responses to violent video clips were associated with activity in a range of different regions, with attentionrelated (parietal lobe) and emotion-related (orbitofrontal lobe) brain activity decreasing over time in violent videos, suggesting neural desensitization. The brain activation image shows the LOFC activation and adaptation. The brain activation image shows that reviewing violent media is an activation response of the LOFC and adaptation to media with different levels of violence. As can be seen from the figure, LOFC adaptation decreases with the increase of video aggression [16].

\section{CONCLUSION}

This paper demonstrates that exposure to media violence has a negative impact on children and teenagers. Although there is no uniform definition of the concept of media violence, it is generally accepted that media violence includes acts that harm others. There aren't a lot of studies and reports on specific groups of people who are attracted to violent media. Currently only factors such as gender and certain personality, like malicious personality, high neuroticism, low likeability and low conscientiousness, traits are considered to be susceptible to violent media. Research in this area should be further strengthened. Although there have been many studies on the effects of violent media over the past few decades, most of the effects have focused on the three parts discussed in this paper, namely that violent media causes aggressive behavior, reduces prosocial behavior and causes desensitization. In the research on aggressive behavior caused by violent media, this paper mainly describes laboratory research and longitudinal research. Studies have shown that violent media can have both short-term and long-term effects on children and adolescents. Children who watch violent TV programs for a long time tend to show higher levels of aggressive behavior during their teenage years and are more likely to participate in criminal behavior as adults. Social cognitive models of social behavior shows that shortterm violent video games reduce prosocial or helping behavior. Other studies have shown that violent media causes children to become less sensitive to identity the pain and suffering of others, which can cause desensitization. In conclusion, studies have been conducted to verify the three kinds of adverse effects of violent videos, especially the point that violent videos lead to aggressive behavior has basically reached a consensus. But there has been little research on the idea that violent videos lead to a decrease in prosocial 
behavior. It is hoped that future research can have more in-depth and precise research results.

\section{ACKNOWLEDGMENT}

I would like to thank Miss Huang for her help during the paper. From the topic of the paper, structure to the first draft, second draft, third draft. Miss Huang has been listening to my ideas, guiding me and helping me correct my mistakes in my paper.

\section{REFERENCES}

[1] Rideout, V. (2015). The common sense census: Media use by tweens and teens.

[2] Anderson, C. A., Berkowitz, L., Donnerstein, E., Huesmann, L. R., Johnson, J. D., Linz, D., Malamuth, N. M., \& Wartella, E. (2003). The Influence of Media Violence on Youth. Psychological Science in the Public Interest, 4(3), $81-110$ https://doi.org/10.1111/j.15291006.2003.pspi_143 3.x

[3] Anderson, C. A., Bushman, B. J., Bartholow, B. D., Cantor, J., Christakis, D., Coyne, S. M.\& Ybarra, M. (2017). Screen violence and youth behavior. Pediatrics, 140(Supplement 2), S142S147.

[4] Anderson, C. A., \& Bushman, B. J. (2018). Media violence and the general aggression model. Journal of Social Issues, 74(2), 386-413.

[5] Greitemeyer, T., \& Sagioglou, C. (2017). The longitudinal relationship between everyday sadism and the amount of violent video game play. Personality and individual differences, 104, 238-242.

[6] Hartmann, T., Möller, I., \& Krause, C. (2015). Factors underlying male and female use of violent video games. New Media \& Society, 17(11), 17771794.

[7] Markey, P. M., \& Markey, C. N. (2010). Vulnerability to violent video games: A review and integration of personality research. Review of General Psychology, 14(2), 82-91.

[8] Anderson, C. A., \& Bushman, B. J. (2001). Effects of violent video games on aggressive behavior, aggressive cognition, aggressive affect, physiological arousal, and prosocial behavior: A meta-analytic review of the scientific literature. Psychological science, 12(5), 353-359.

[9] Hollingdale, J., \& Greitemeyer, T. (2014). The effect of online violent video games on levels of aggression. PLoS one, 9(11), e111790.
[10] Coyne, S. M. (2016). Effects of viewing relational aggression on television on aggressive behavior in adolescents: A three-year longitudinal study. Developmental psychology, 52(2), 284.

[11] Gentile, D. A., Swing, E. L., Anderson, C. A., Rinker, D., \& Thomas, K. M. (2016). Differential neural recruitment during violent video game play in violent-and nonviolent-game players. Psychology of Popular Media Culture, 5(1), 39.

[12] Penner, L. A., Dovidio, J. F., Piliavin, J. A., \& Schroeder, D. A. (2005). Prosocial behavior: Multilevel perspectives. Annu. Rev. Psychol., 56, 365-392.

[13] Coyne, S. M., Warburton, W. A., Essig, L. W., \& Stockdale, L. A. (2018). Violent video games, externalizing behavior, and prosocial behavior: A five-year longitudinal study during adolescence. Developmental psychology, 54(10), 1868.

[14] Krahé, B., \& Möller, I. (2011). Links between selfreported media violence exposure and teacher ratings of aggression and prosocial behavior among German adolescents. Journal of Adolescence, 34(2), 279-287.

[15] Brockmyer, J. F. (2015). Playing violent video games and desensitization to violence. Child and Adolescent Psychiatric Clinics, 24(1), 65-77.

[16] Strenziok, M., Krueger, F., Deshpande, G., Lenroot, R. K., Meer, E. van der, \& Grafman, J. (2011). Fronto-parietal regulation of media violence exposure in adolescents: a multi-method study. Social Cognitive and Affective Neuroscience, 6(5), 537-547.

[17] Fanti, K. A., Vanman, E., Henrich, C. C., \& Avraamides, M. N. (2009). Desensitization to media violence over a short period of time. Aggressive Behavior, 35(2), 179-187. 